\title{
Brief Analysis of the Application and Funding Projects of National Natural Science Foundation of China in a Comprehensive Teaching Hospital, 2011-2019
}

\author{
Qiang $\mathrm{Hu}^{* 1}$, Hui Peng* ${ }^{1}$, Lin $\mathrm{Ma}^{1}$, Qiqi Shen ${ }^{1}$, Shengsheng Tao ${ }^{1}, \& \mathrm{Kun} \mathrm{Lv}^{1}$ \\ ${ }^{1}$ Department of Science and Technology, The First Affiliated Hospital of Wannan Medical College (Yijishan \\ Hospital of Wannan Medical College), Wuhu, Anhui Province, China \\ *These authors contributed equally to this work. \\ Correspondence: Kun Lv, Department of Science and Technology, The First Affiliated Hospital of Wannan \\ Medical College (Yijishan Hospital of Wannan Medical College), Wuhu, Anhui Province, China. E-mail: \\ lvkun315@126.com
}

Received: July 17, $2020 \quad$ Accepted: August 28, $2020 \quad$ Online Published: September 24, 2020

doi:10.5539/ass.v16n10p44 URL: https://doi.org/10.5539/ass.v16n10p44

\begin{abstract}
The National Natural Science Foundation of China (NSFC) plays an important role in supporting scientific research. A descriptive study was performed to understand the situation supported by the NSFC in a comprehensive teaching hospital during 2011 to 2019. The relevant situation was statistically analyzed during 2011-2019, including the amount of applications and grant, funding rate, and appropriation. During the past 9 years, the total funding rate of the science foundation was $14.29 \%$ (51/357), with a total appropriation of 189.485 ten thousands Yuan. In the past 9 years, the number of funding applications and the number of project approval showed an overall trend of fluctuation, with the project funding rate between $7.69 \%$ and $27.27 \%$, and showed no significant changing trend in the funding rate during 2011-2019 ( $\left.\chi_{\text {trend }}^{2}=0.54, P=0.464\right)$. We found that the approval rates of male (16.30\%) and doctoral applicants (20.98\%) were significantly higher than those of female (7.41\%) and non-doctoral applicants (5.26\%). Hospital need to introduce doctoral talents, increase investment in scientific research, and improve the motivation of medical staff to apply for the NSFC.
\end{abstract}

Keywords: National Natural Science Foundation of China (NSFC), funded, teaching hospital, descriptive study

\section{Introduction}

The National Natural Science Foundation of China (NSFC) plays an important role in supporting scientific research (Lei et al., 2019; Liu et al., 2019), which is a driving force for the improvement of National scientific and technological level and the original innovation of knowledge, and one of the main channels for supporting basic research in China. Since its establishment in 1986, the Fund has played a great role in promoting the development of basic disciplines in the field of science, the development of applied science and the cultivation of talents (Zhu, 2004). At present, whether or not to obtain fund project funding has become not only an important indicator to measure the scientific research ability of researchers, but also an important indicator to evaluate the scientific research ability and scientific management level of various scientific research institutions.

Yijishan Hospital of Wannan Medical College is a tertiary care teaching hospital with 2230 beds and admissions of approximately 80000 patients per year, serving a further 1320000 outpatients each year (Tao et al., 2014). It is the largest provincial medical center and medical technical guidance center integrating medical treatment, teaching, scientific research, prevention, rehabilitation and first aid in south Anhui and Wanjiang areas of Anhui Province, China. In the process of continuous development and growth, the hospital has always adhered to the concept of invigorating the hospital by science and technology, emphasized the leading role of scientific research in hospital development, and made every effort to seek leapfrog development of scientific research. The application and management of the National Natural Science Fund is the key.

This paper systematically reviewed the application and project approval of the National Natural Science Foundation of the hospital in the past nine years (2011-2019), conducted statistical analysis on the gender of the project leader, degree and project category, and introduced the relevant experience and measures of the hospital from the aspects of application mobilization, talent team construction, and relevant management policies. 


\section{Methods}

A descriptive study was performed to understand the situation supported by the NSFC in a comprehensive teaching hospital during 2011 to 2019. The relevant situation was statistically analyzed during 2011-2019, including the amount of applications and grant, funding rate, and appropriation. Funding rate was calculated as the number of approved projects divided by the total application number.

The Chi-square test was used to assess the difference in funding rates amongst different characteristics of the applicant. Mantel-Haenszel Chi-square test for the funding rates trend by years was performed. A two-tailed p-value of $<0.05$ was considered statistically significant.

\section{Results}

\subsection{Application and Funding Status}

During the past 9 years, the total funding rate of the science foundation was $14.25 \%$ (57/357), with a total appropriation of 189.485 ten thousands Yuan. In the past 9 years, the number of funding applications and the number of project approval showed an overall trend of fluctuation, with the project funding rate between $7.69 \%$ and $27.27 \%$, and showed no statistically significant temporal trend $\left(\chi_{\text {trend }}^{2}=0.54, P=0.464\right)$ (Figure 1).

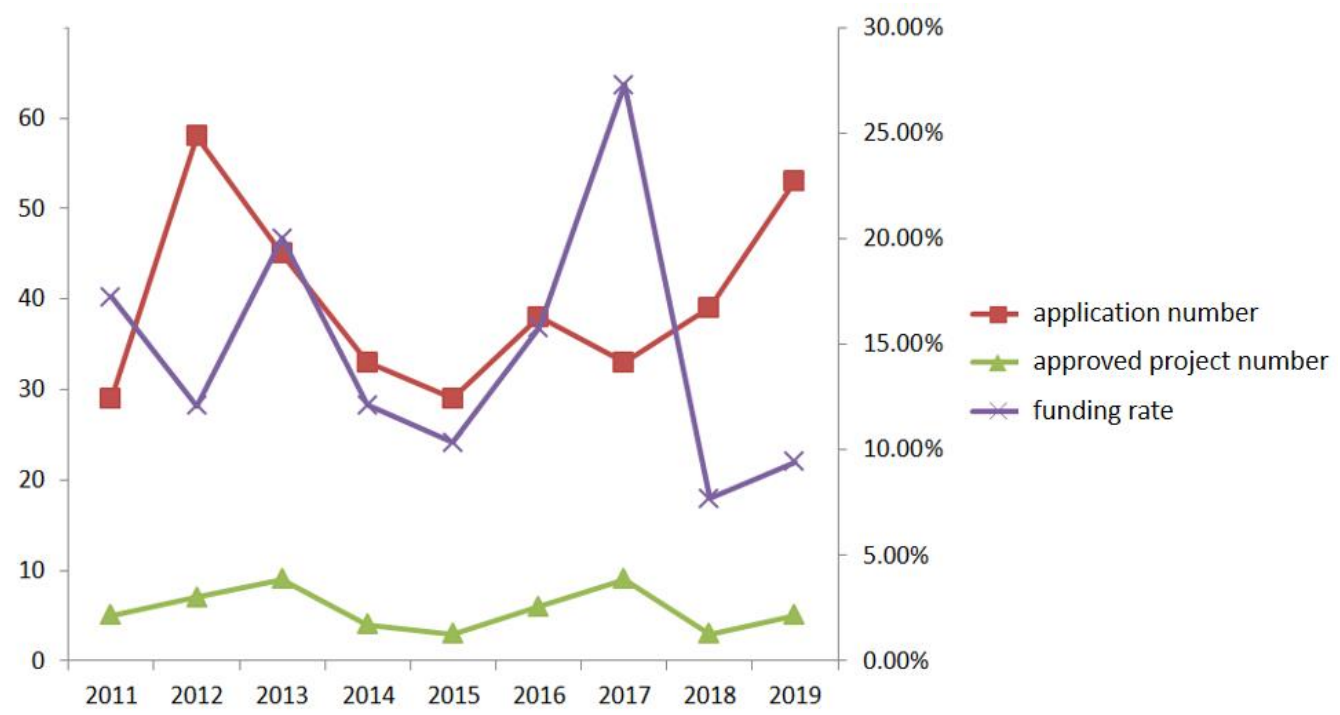

Figure 1. Time trend for total application number, approved project number, and funding rate of NSFC, 2011-2019

\subsection{Funding Rates Amongst Different Characteristics of the Applicant}

It showed that the funding rates of male $(16.30 \%)$ and doctoral applicants $(20.98 \%)$ were significantly higher than those of female $(7.41 \%)$ and non-doctoral applicants (5.26\%) (Table 1).

Table 1. Funding rates amongst different characteristics of the applicant

\begin{tabular}{ccccc}
\hline Items & Total application number & Number of approved projects (\%) & $\chi^{2}$ & $P$ \\
\hline Sex & & & & \\
Male & 276 & $45(\mathbf{1 6 . 3 0})$ & 4.04 & 0.045 \\
Female & 81 & $6(7.41)$ & & \\
Academic degree & & & & \\
Doctor & 205 & $43(\mathbf{2 0 . 9 8})$ & -- & $<0.001^{\text {a }}$ \\
Master & 122 & $8(6.56)$ & & \\
Others & 30 & $0(0.00)$ & & \\
Type of projects & 195 & $26(13.33)$ & 0.32 & 0.573 \\
General Program & 162 & $25(15.43)$ & & \\
Youth Program & & &
\end{tabular}

Note: ${ }^{\text {a}}$ Fisher's $P$ value. 


\section{Discussion}

The NSFC is one of the main sources of funds for basic research activities carried out by researchers in affiliated hospitals of universities. With the continuous support of the fund, Yijishan Hospital of Wannan Medical College has made great progress in basic research, discipline development and scientific research platform construction in recent years.

There are some experience and measures in the application and management of hospital science fund. (1) Actively organize and mobilize, and formulate a clear reward and punishment mechanism. The declaration and mobilization work was carried out half a year in advance, and relevant personnel were contacted in various ways to learn about the status quo of their research work. In view of the low enthusiasm of clinical researchers in declaration, the hospital increased the corresponding incentive mechanism and punishment measures, such as the establishment of a declaration and reward system for all the applicants. (2) Combine introduction and training, strengthen the construction of talent team. In view of the shortage of scientific research talents in recent years, especially the shortage of doctoral talents introduction and training, the hospital has intensified the efforts of talent introduction and significantly improved the treatment of introduced talents. Meanwhile, it has also issued policies related to on-the-job academic education for employees to encourage them to continue their studies and improve their scientific research quality. (3) Multiple measures to improve the quality of project tender. Each declaration must go through multiple formal reviews, looking for and reviewing possible format problems in each detail of the declaration, and ensuring that each tender submitted to NSFC is not screened out due to format problems. We will actively organize training and briefing sessions for the Application of the National Natural Resources Fund and strengthen academic exchanges. (4) Build scientific research platform to provide support for basic research. Build a platform for basic research, provide funding site and policy support, pay attention to the accumulation of early work to lay a foundation for the project.

In this present study we collect data and describe the situation supported by the NSFC in the Yijishan Hospital of Wannan Medical College during 2011 to 2019. It shows that during the past 9 years, the total funding rate of the science foundation was $14.25 \%$, with a total appropriation of 189.485 ten thousands Yuan. There is no significant changing trend in the funding rate during 2011- 2019. We find that the approval rates of male and doctoral applicants were significantly higher than those of female and non-doctoral applicants.

Although in recent years the hospital has gradually increased its investment in the declaration and management of the NSFC, the project funding has not yet formed a steady development trend. Next, hospital should strive to build a practical and effective talent management system, provide software and hardware support for the construction of talent team; enhance introduction and training of doctoral talents, strengthen the guidance and training of female researchers, and endeavor to realize the leapfrog development of hospital scientific research fund.

\section{Acknowledgments}

This work was supported by National Natural Science Foundation of China (No.81772180).

\section{References}

Lei, R., Liu, Q., Wang, Y., Wang, H., \& Shen, Y. X. (2019). Analysis of major programs in the field of health science funded by the National Natural Science Foundation of China between the years 2010 and 2018. Ann Transl Med, 7(12), 268. https://doi.org/10.21037/atm.2019.05.66

Liu, Y., Gao, Z., Wang, H., Wang, J. B., Shen, J., \& Wang, C. R. (2019). Analysis of projects funded by the National Natural Science Foundation of China during the years of 2014-2018. Ann Transl Med, 712(12), 267. https://doi.org/10.21037/atm.2019.05.63

Zhu, Z. (2004). Basic research must come first. An interview with Zuoyan Zhu, Vice President of the National Natural Science Foundation of China and member of the Chinese Academy of Sciences. Interviewed by Holger Breithaupt and Caroline Hadley. EMBO Rep, 5, 442-445. https://doi.org/10.1038/sj.embor.7400163

Tao, X. B., Qian, L. H., Li, Y., Wu, Q., Ruan, J. J., \& Cai, D. Z. (2014). Hospital-acquired infection rate in a tertiary care teaching hospital in China: a cross-sectional survey involving 2434 inpatients. Int J Infect Dis, 27, 7-9. https://doi.org/10.1016/j.ijid.2014.05.011

\section{Copyrights}

Copyright for this article is retained by the author(s), with first publication rights granted to the journal.

This is an open-access article distributed under the terms and conditions of the Creative Commons Attribution license (http://creativecommons.org/licenses/by/4.0/). 